\title{
Random Risk Appetite
}

\begin{abstract}
Samih Antoine Azar ${ }^{1, *}$
${ }^{1}$ Faculty of Business Administration \& Economics, Haigazian University, Mexique Street, Kantari, Beirut, Lebanon

*Correspondence: Faculty of Business Administration \& Economics, Haigazian University, Mexique Street, Kantari, Beirut, Lebanon. Tel: 961-134-9231. E-mail: samih.azar@haigazian.edu.lb
\end{abstract}

Received: June 27, 2018 Accepted: July 24, 2018 Published: August 7, 2018

doi: 10.5296/rae.v10i3.13331 URL: https://doi.org/10.5296/rae.v10i3.13331

\begin{abstract}
There is a burgeoning literature on the randomness of the coefficient of relative risk aversion (CRRA). This paper is in line with such a research agenda. Modelling risk aversion, or its converse, risk appetite, as a random variable violates one of the fundamental principles of economics, in general, and of the behavior under risk in particular, and which is constant preferences. This paper argues otherwise. Both conditional and unconditional tests are carried out to identify the CRRA. A battery of econometric procedures is attempted. The paper postulates that the CRRA follows a normal distribution, with the first two statistical moments derived from the empirical results. The CRRA is found to follow a normal distribution with mean 2.57, and with a standard error of 0.454 . Surprisingly, the $95 \%$ confidence interval does not include a CRRA of +1 , or log utility. However the richness of the approach compensates for this caveat.
\end{abstract}

Keywords: risk appetite, risk aversion, probability density function of risk aversion, consumption-CAPM, US market, Euler equations, unconditional and conditional models, sensitivity and robustness of results

JEL Codes: D81, G12, C22, C26 


\section{Introduction}

The notion of utility is central in economics and its origination dates back to the works of Jeremy Bentham in the nineteenth century. Bernoulli, however, is credited to be the father of the concept of expected utility. Two centuries later, expected utility was used by Neumann and Morgenstern (1944) to study individual behavior under risk. This paradigm endured for a significant part of the twentieth century. It did not last long and has been challenged, but was not totally replaced, by the advent of behavioral economics. In this respect, two researchers were awarded Nobel Prizes for their work related to behavioral finance: Kahneman in 2002 and Thaler in 2017. Another 1990 Nobel laureate, Markowitz, is sometimes considered to be a precursor of this strand of the literature. Whether you believe in expected utility, or in loss aversion and prospect theory, it is crucial to possess a measure for the risk aversion coefficient or, perhaps, for more than one measure. A whole literature has evolved on finding the magnitude of the coefficient of relative risk aversion (French et al., 1987; Bollerslev et al., 1988; Evans, 2004a. 2004b; Evans and Sezer (2004); Azar, 2006, 2007, 2010a, 2014; Chetty, 2006; Tödter, 2008; Das and Sarkar, 2010; Chiappori and Paiella, 2011). In parallel to this literature, and in the financial markets, the business press was keen to describe inter-daily and intra-daily stock market fluctuations by invoking changes in the risk appetite of traders. The issue at stake was no more how big is risk aversion, but whether there is a constancy in risk aversion. Different authors come out each with his own estimates. The only thread of truth lies in asking which estimate is the best, like in a beauty contest. This issue is not simply a theoretical question but it has relevance to other sectors in the economic realm from public finance, insurance, asset pricing, risk management, and policy implementation.

Some dispersed research has assumed or modeled that the risk aversion coefficient is not a constant. For example Yoon and Byun, (2012) find different risk aversion coefficients for options on three stock market indices; Gandelman and Hernández-Murillo (2015) calculates different coefficients for the 75 countries in their sample; and Berger and Turtle (2009) and Conine et al. (2017) estimate time-varying coefficients. Azar (2010b, 2011, and 2017a) was more vocal and posited that the risk aversion coefficient is a random variable, i.e. a variable that follows a probability density function. The mean of this distribution is what researchers are trying to estimate while it is the whole distribution that is relevant, keeping with what the business press believes in. The purpose of this paper is to provide for such a distribution by relying on the inherently different estimates of the coefficient of relative risk aversion (CRRA) obtained from alternative econometric procedures applied on the same Euler equations.

The paper starts by rehearsing some basic issues (section 2) and by presenting the evidence that classic rules to estimate the CRRA produce more than one solution (section 3), and proceeds with estimating the Euler equations by changing the econometric approach (section 4). The average and standard deviations from this array of econometric procedures will be considered to represent the first two moments of the risk aversion probability spectrum. The last section concludes. 


\section{Macrothink}

\section{The Background}

Azar (2010b, and 2011) use the setup in Lucas (1987) for the welfare social cost of consumption fluctuations, and apply the same method to the social cost of systematic risk and to the social cost of the Euro currency risk. The analysis starts by minimizing the following difference relation:

$$
E[U(\widetilde{W}(1+\theta))]-U[E(\widetilde{W})]
$$

Where $\widetilde{W}$ is the stochastic end-of-period wealth, $E($.$) is the expectation operator, and U($. is the utility functional form. The symbol $\theta$ is the proportionate upward shift in stochastic wealth that would be required to make the representative consumer indifferent between a random systematic shock to wealth, which is the left-hand side of equation (1) and a non-random allocation of wealth, which is the right-hand side of the equation (Ljungqvist and Sargent (2004: 103). Azar (2010b, and 2011) derives the solution which equals: $\theta=\pi /(1+r f)$, where $\pi$ is the risk premium and $r f$ is the risk-free asset return. Based on the above, Azar simulates the CRRA and obtains the risk-free asset return and the risk premium, from which the value of $\pi$ is retrieved. Hence Azar finds an inverse relation between the CRRA and the risk-free asset by varying the CRRA. As a result $\theta$ is calculated. The same inverse relation is obtained by a similar procedure in Azar (2017a) by pre-specifying volatility and the CRRA. This paper argues that the volatility in the stock market is a random variable, and varies this volatility for 14 cases between $3.6 \%$, the historical volatility of per capita US consumption, and a grand value of $35 \%$. The CRRA is also varied from 0.2, by increments of 0.2, till the figure 5. With this setup Azar finds that volatility and the risk-free rate vary in tandem. He also finds that the CRRA is indeterminate, taking different values with many risk-free returns between $3.6 \%$ and $4 \%$. Azar concludes that modeling risk aversion as a random variable provides for richer results.

Azar (2017b) varies preferences between the current period and the future period. He derives a relation between the log of current US aggregate consumption and the gross return on a risk-free asset. Azar finds evidence for his model that differentiates the short run from the long run in preferences.

Mehra and Prescott (2008) derive the following equation for the gross riskless return $R f$, where the subscript $c$ corresponds to real per capita consumption expenditures, where $\mu_{c}$ and $\sigma_{c}^{2}$ are the first two moments of consumption growth, $\beta$ is the discount factor, and $\gamma$ the CRRA:

$$
\log R f=-\log \beta+\gamma \mu_{c}-\frac{1}{2} \gamma^{2} \sigma_{c}^{2}
$$

This equation can be written as:

$$
-\frac{1}{2} \gamma^{2} \sigma_{c}^{2}+\gamma \mu_{c}-\log R f-\log \beta=0
$$


It is reasonable to assume that $\log R f+\log \beta=0$, leading to the following:

$-\frac{1}{2} \gamma^{2} \sigma_{c}^{2}+\gamma \mu_{c}=0=\gamma\left(\mu_{c}-\frac{1}{2} \gamma \sigma_{c}^{2}\right)$

Solving for $\gamma$ one obtains two roots: (1) $\gamma=0$, and (2) $\gamma=2 \mu_{c} / \sigma_{c}^{2}$

Usually researchers ignore the first solution. But this example shows that risk neutrality, $\gamma=0$, is a second solution. As we will be seeing later two solutions for the Euler equations are hardly a rare phenomenon.

Starting from the maximization of consumption:

Maximize: $U\left(C_{0}\right)+\beta E\left[U\left(C_{1}\right)\right]$

And, by assuming that $U(C)=C^{\alpha} / \alpha$, we can differentiate the total utility relative to $\alpha$ and obtain:

$U_{\alpha}\left(\alpha, C_{0}\right)+\beta E U_{\alpha}\left(\alpha, C_{1}\right)=0$

This first-order condition can be written:

$\alpha \log \left(C_{0}\right) C_{0}^{\alpha}-C_{0}^{\alpha}+\beta E\left[\alpha \log \left(C_{1}\right) C_{1}^{\alpha}-C_{1}^{\alpha}\right]=0 \quad$ with $\quad \alpha \neq 0$

This equation can be written:

$E\left\{\alpha \log \left(C_{0}\right) C_{0}^{\alpha}-C_{0}^{\alpha}+\beta\left[\alpha \log \left(C_{1}\right) C_{1}^{\alpha}-C_{1}^{\alpha}\right]\right\}=0$

We start by a numerical analysis. Replacing actual per capita consumption in the above equation and setting the sum to zero we can solve the equation for $\alpha$ by using the SOLVER command in Excel. The algorithm provides for an $\alpha=0.12076$ in absolute terms. However, this solution is not stable. Other solutions are possible: between 13.5 and 17.55, and between 47.5 and 50.825. If we define that the CRRA $=\gamma=1-(\alpha)$, then the CRRA has multiple solutions.

\section{The Empirical Results (1)}

This part of the paper is organized as follows. First, the exercise performed by Kocherlakota (1996) will be repeated here in order to make sure that our sample size and the magnitude of all our variables are in conformity to those of Kocherlakota and that they result in the same or in similar inferences.

Kocherlakota assumes variable coefficients of relative risk aversion (CRRA), studies the unconditional forms of the CCAPM Euler equations, calculates all the inherent deviations from the model and tests the average error for statistical significance. When the average error 
becomes statistically insignificant the hypothesis that the theoretical model is true fails to be rejected. From the literature it is expected that this occurs at a quite large, and unreasonable, CRRA.

Second, the Consumption-CAPM Euler equations are estimated unconditionally and conditionally by more than one econometric procedure: GMM, OLS, Seemingly Unrelated Regressions, 2-Stage Least Squares, and 3-Stage Least squares. There are three Euler equations as follows:

Total return Euler equation: $\beta E\left[\left(\frac{c_{\mathrm{t}}}{c_{\mathrm{t}+1}}\right)^{\gamma}(1+\tilde{r})\right]=1$

Risk-free Euler equation: $\beta E\left[\left(\frac{c_{t}}{c_{t+1}}\right)^{\gamma}\right](1+r f)=1$

Euler equation on the asset premium: $E\left[\left(\frac{c_{t}}{c_{t+1}}\right)^{\gamma}(\tilde{r}-r f)\right]=0$

In these Euler equations $C$ is the US per capita aggregate consumption, $\tilde{r}$ is the risky return, $r f$ is the riskless return, $\beta$ is the subjective discount factor for utility, and $\gamma$ is the CRRA. The utility function is specified to be:

$$
U(C)=\frac{c^{1-\gamma}-1}{1-\gamma}
$$

The method employed by Kocherlakota (1996) is replicated for the three Euler equations, using data retrieved from the web page of Professor Robert Shiller. The data is annual and whenever possible it is in real, inflation-adjusted, terms. This applies to real per capita consumption, real market equity returns, and real risk-free returns. The sample size is from 1890 to 2009, and consists of 120 observations. There are three Euler equations: the total return, the risk-free rate, and the risk premium. Surprisingly the first Euler equation is not tested by Kocherlakota. This may be due to the observation that this equation has produced a reasonable and satisfactory CRRA. It is amazing to notice that results which do not support the research hypothesis are generally omitted, or ignored, or disregarded. Unfortunately, this is the fate of most applied work.

Table 1 is composed of three parts that correspond to each one of the three Euler equations. In each part there are three columns: the imposed CRRA, the average unconditional error for such a CRRA and the actual p-value of a test whose null hypothesis is that the average error is zero.

In what concerns the first Euler equation, the one for the total equity return, stated in equation (2), the results are, for the least, surprising. This comes from the observation that the average error is insignificant for all values of the CRRA between 0.5 and 2.7, giving credence to the theory. The average error remains significant till a CRRA of 22. For CRRAs above 22, from 23 to 30, the average error is insignificant once again. This means that a CRRA between 23 
and 30 provides for satisfactory results, i.e. the theoretical model is not rejected. This behavior in the data was not documented elsewhere in any of the research on the subject matter. The implication is that our examination shows that the theoretical model has more than one solution. One of the two is reasonable (below 2.7) while the other one is sharply and appallingly too high (above 22).

Table 1. Testing the Average Error of the Euler Equations for Statistical Significance. The Euler Equations are Obeyed When the Average Error is Statistically Insignificant

\begin{tabular}{|c|c|c|c|c|c|c|c|c|}
\hline \multicolumn{3}{|c|}{$\begin{array}{l}\text { Real equity return Euler equation } \\
\qquad \beta=0.96\end{array}$} & \multicolumn{3}{|c|}{$\begin{array}{l}\text { Real risk-free return Euler equation } \\
\qquad \beta=0.98\end{array}$} & \multicolumn{3}{|c|}{ Equity premium Euler equation } \\
\hline CRRA & $\begin{array}{c}\text { Average } \\
\text { error }\end{array}$ & $\begin{array}{l}\text { Actual } \\
\text { p-value }\end{array}$ & CRRA & $\begin{array}{l}\text { Average } \\
\text { error }\end{array}$ & $\begin{array}{l}\text { Actual } \\
\text { p-value }\end{array}$ & CRRA & $\begin{array}{l}\text { Average } \\
\text { error }\end{array}$ & $\begin{array}{l}\text { Actual } \\
\text { p-value }\end{array}$ \\
\hline 0.1 & +0.0316 & 0.0542 & 0.1 & -0.0030 & 0.5305 & 0.2 & +0.0566 & 0.0012 \\
\hline 0.25 & +0.0280 & 0.0815 & 0.2 & -0.0049 & 0.3033 & 0.5 & +0.0552 & 0.0015 \\
\hline 0.5 & +0.0221 & 0.1551 & 0.3 & -0.0068 & 0.1584 & 2.0 & +0.0480 & 0.0048 \\
\hline 0.8 & +0.0152 & 0.3107 & 0.4 & -0.0088 & 0.0773 & 3.0 & +0.0434 & 0.0104 \\
\hline 2.0 & -0.0110 & 0.4150 & 0.5 & -0.0107 & 0.0362 & 4.0 & +0.0389 & 0.0217 \\
\hline 2.5 & -0.0211 & 0.1080 & 0.6 & -0.0126 & 0.0167 & 5.0 & +0.0344 & 0.0435 \\
\hline 2.6 & -0.0231 & 0.0780 & 0.7 & -0.0144 & 0.0077 & 5.1 & +0.0340 & 0.0465 \\
\hline 2.7 & -0.0251 & 0.0553 & 0.8 & -0.0163 & 0.0037 & 5.2 & +0.0335 & 0.0497 \\
\hline 2.8 & -0.0271 & 0.0387 & 0.9 & -0.0182 & 0.0018 & 5.3 & +0.0331 & 0.0531 \\
\hline 2.9 & -0.0290 & 0.0266 & 1.0 & -1.0198 & 0.0000 & 5.4 & +0.0326 & 0.0566 \\
\hline 3.0 & -0.0310 & 0.0181 & 2.0 & -0.0374 & 0.0000 & 5.5 & +0.0322 & 0.0604 \\
\hline 4.0 & -0.0494 & 0.0003 & 4.0 & -0.0677 & 0.0000 & 6.0 & +0.0300 & 0.0824 \\
\hline 5.0 & -0.0663 & 0.0000 & 10.0 & -0.1244 & 0.0004 & 7.0 & +0.0256 & 0.1461 \\
\hline 10.0 & -0.1304 & 0.0000 & 12.0 & -0.1324 & 0.0024 & 8.0 & +0.0213 & 0.2407 \\
\hline 17.0 & -0.1662 & 0.0006 & 14.0 & -0.1347 & 0.0108 & 9.0 & +0.0169 & 0.3683 \\
\hline 20.0 & -0.1622 & 0.0083 & 15.0 & -0.1338 & 0.0211 & 11.0 & +0.0079 & 0.6978 \\
\hline 22.0 & -0.1527 & 0.0345 & 16.0 & -0.1313 & 0.0389 & 12.0 & +0.0034 & 0.8761 \\
\hline 23.0 & -0.1456 & 0.0629 & 17.0 & -0.1273 & 0.0674 & 13.0 & -0.0013 & 0.9536 \\
\hline 24.0 & -0.1370 & 0.1067 & 18.0 & -0.1217 & 0.1099 & 17.0 & -0.0219 & 0.4698 \\
\hline 25.0 & -0.1267 & 0.1691 & 19.0 & -0.1145 & 0.1693 & 20.0 & -0.0401 & 0.2996 \\
\hline \multirow[t]{5}{*}{30.0} & -0.0471 & 0.7364 & 20.0 & -0.1055 & 0.2468 & 25.0 & -0.0791 & 0.1888 \\
\hline & & & & & & 30.0 & -0.1355 & 0.1582 \\
\hline & & & & & & 40.0 & -0.3524 & 0.1611 \\
\hline & & & & & & 50.0 & -0.8894 & 0.1834 \\
\hline & & & & & & 100.0 & -105.16 & 0.2599 \\
\hline
\end{tabular}

Note: The yearly sample size is $120(1890 / 2009)$.

The second part of Table 1 is about the risk-free return Euler equation, stated in equation (3). Again the results are surprising, in that they show two solutions. A CRRA between 0.1 and 0.4 does not lead to rejection of the model, although CRRAs so low may not be realistic enough. The second solution is with a CRRA above 16. Such estimates are not reasonable. The acceptable range for the CRRA is to be less than 10. Using the same methodology 
Kocherlakota finds similar results for the first solution. However, he stops his simulation at a CRRA of 10. To get the second solution he has to test for CRRAs higher than 10.

The third part of Table 1 is about the third and last Euler equation, stated in equation (4). There is only one solution in the adopted range of 0.2 to 100. This solution is lower than the one in Kocherlakota who finds a CRRA of 7. Our results are that any value for the CRRA higher than 5.2 is consistent with the model. Not only that, but the table shows that a CRRA of 50 is also consistent with the underlying model.

Therefore, Table 1 has presented, concordant to the literature, evidence that very high CRRAs are consistent with the model. Nonetheless, this is not the whole story. In two Euler equations, the solution was not unique. And for one Euler equation the theoretical model fails to be rejected. This makes the CCAPM puzzle more puzzling than before.

\section{Empirical Results (2)}

This part of the paper will estimate the CRRA with an array of econometric procedures some unconditional others conditional, and two cases of instrumental variables. In Table 2 estimation of the Euler equations is undertaken by unconditional GMM. We have two parameter coefficients: the discount factor and the CRRA. We chose to fix the discount factor and solve for the CRRA. The allowed discount factors are simulated from 0.95 to 1.05 , in steps of 0.01 . There are eleven different scenarios. The choice of a discount factor that is higher than +1 may seem surprising. It should not be because a discount factor higher than 1 is permissible in this model as competitive markets may exist with such a derogation to intuition (Kocherlakota, 1990; Benninga and Protopappadakis, 1990).

We begin by the first Euler equation, equation (2). The estimates of the CRRA are between 2.57 and 3.79 and increase as the discount factor increases. This is as expected: a higher discount factor is equivalent to a parallel upward shift of the gross return on equity. Therefore, to restore equilibrium the risk aversion coefficient must increase. Anecdotal evidence about Fisher Black, reported by Mehra and Prescott (2008: 22), is that Black suggested that a discount factor of 0.55 resolves the equity premium puzzle. In our simulations, a plausible discount factor of 0.95 produces the minimum CRRA. However, the usual discount factor is selected in this research to be higher, at 0.98 (see Table 1). For such a discount factor the CRRA is estimated to be 2.97. For a discount factor of 0.99 the implied estimate is 3.1. All eleven estimates of the CRRA are statistically highly significant, with the smallest t-statistic at 7.5907. The t-statistics increase along with the CRRA. Table 2 also reports Durbin-Watson statistics. Since the data is yearly a one period During-Watson statistic is enough to test for serial correlation. The minimum value for this statistic is 1.7855 . This is higher than the higher limits of that statistic, i.e. $1.637(1 \%)$ and $1.747(5 \%)$. This is evidence that our econometric procedure is sound. Finally the Schwarz information criterion is reported in the table. This criterion, if minimized, signals that the best specification is the one with a discount factor of 0.97 . 
Table 2. Unconditional GMM Estimates for the Coefficient of Relative Risk Aversion (CRRA) or $\gamma$

\begin{tabular}{ccc}
\hline $\begin{array}{c}\text { Beta } \\
(\beta)\end{array}$ & Real equity return Euler equation & \multicolumn{1}{c}{ Real risk-free return Euler equation } \\
\hline 0.95 & $2.5697(7.5907)[0.0000]\{1.7855\}\langle-0.992932\rangle$ & $-0.4658(-3.4111)[0.0009]\{1.0961\}\langle-2.811029\rangle$ \\
0.96 & $2.7064(8.0653)[0.0000]\{1.8315\}\langle-1.001249\rangle$ & $-0.3336(-2.6211)[0.0099]\{1.1360\}\langle-2.942182\rangle$ \\
0.97 & $2.8397(8.5068)[0.0000]\{1.8689\}\langle-1.002091\rangle$ & $-0.2046(-1.6933)[0.0930]\{1.1536\}\langle-3.036065\rangle$ \\
0.98 & $2.9698(8.9103)[0.0000]\{1.8967\}\langle-0.995401\rangle$ & $-0.0788(-0.6702)[0.5040]\{1.1379\}\langle-3.079651\rangle$ \\
0.99 & $3.0966(9.2720)[0.0000]\{1.9141\}\langle-0.981290\rangle$ & $0.0438(0.3718)[0.7107]\{1.0860\}\langle-3.065754\rangle$ \\
1.00 & $3.2202(9.5895)[0.0000]\{1.9212\}\langle-0.960032\rangle$ & $0.1634(1.3465)[0.1807]\{1.0066\}\langle-2.996407\rangle$ \\
1.01 & $3.3406(9.8619)[0.0000]\{1.9182\}\langle-0.932042\rangle$ & $0.2801(2.1906)[0.0304]\{0.9152\}\langle-2.881861\rangle$ \\
1.02 & $3.4580(10.089)[0.0000]\{1.9057\}\langle-0.897849\rangle$ & $0.3938(2.8791)[0.0047]\{0.8260\}\langle-2.736096\rangle$ \\
1.03 & $3.5724(10.274)[0.0000]\{1.8849\}\langle-0.858063\rangle$ & $0.5046(3.4184)[0.0009]\{0.7472\}\langle-2.572354\rangle$ \\
1.04 & $3.6839(10.419)[0.0000]\{1.8569\}\langle-0.813344\rangle$ & $0.6126(3.8308)[0.0002]\{0.6814\}\langle-2.400865\rangle$ \\
1.05 & $3.7925(10.526)[0.0000]\{1.8229\}\langle-0.764367\rangle$ & $0.7179(4.1223)[0.0001]\{0.6282\}\langle-2.228537\rangle$ \\
\hline
\end{tabular}

Notes: The yearly sample size is 120 (1890/2009). The t-statistics are in ( ). The two-tailed actual p-values are in [ ]. The Durbin Watson statistics are in \{ ?. The Schwarz information criteria are in ( ) The $1 \%$ critical values for the Durbin-Watson statistic for a sample size of 150 are 1.611-1.637. The 5\% critical values for the Durbin-Watson statistic for a sample size of 150 are 1.720-1.747.

If the same analysis is applied to the second Euler equation, equation (3), the results are concordant to the evidence in Table 1. At low discount factors the CRRA is estimated to be statistically insignificant and negative. At a discount factor of 0.96 the CRRA becomes statistically significant but still negative. Starting from a discount factor of 1, up to 1.05, the CRRA increases monotonously from 0.2801 to 0.7179 . For all these values the t-statistics denote high statistical significance. The lowest t-statistic is 2.1906 and has an actual two-tailed p-value of 0.0304. Unfortunately the models are plagued with heavy positive serial correlation, the maximum value of the Durbin-Watson statistic being 1.1536. Finally the Schwarz information criterion selects the model with a discount rate of 0.98. At this discount factor the CRRA is negative, close to zero, but statistically insignificant.

The third Euler equation, stated in equation (4), and which is for the equity premium, has only one parameter to estimate. The discount factor drops out of the equation. Hence we have only one estimate of the CRRA: 3.8973 having a t-statistic of 2.4810, an actual two-tailed p-value of 0.0145 (Table 3). The Durbin-Watson statistic of 1.6408 gives ambiguous results. The least one can say is that there is a marginally high probability that the hypothesis of no serial correlation stands out.

As a summary of the analysis for Tables 2 and 3 the unconditional estimates of the CRRA seem to be reasonable, and the optimal discount factor seems to be acceptable. There is no trace for financial anomalies and financial puzzles. The only discordant news is that positive serial correlation exists in the risk-free rate Euler equation. The results are still puzzling if one combines the results in Table 1 with those in Table 2. In Table 1 the obtained CRRAs are outside the reasonable margin, and in two cases out of three there is more than one solution. 


\section{MlMacrothink}

In Table 2 the estimates are overall reasonable. The puzzle lies in the answer to the following question: why is there such a disparity between results? The usual response to similar outcomes in the literature is that the econometric procedure in Table 2, which is GMM, is highly sensitive to small changes, highly sensitive to sample sizes, and highly sensitive to the presence of conditionality or otherwise.

In Table 3 the three Euler equations are each separately estimated by OLS and Seemingly Unrelated Regression (SUR). Since these two econometric procedures do not change with conditionality there is a unique output whatever the instrumental variables that are applied. We already discussed the results pertaining to the equity premium Euler equation. The results for the total return equation do not show anomalies. The estimated discount factor is 0.9661 and it has a very high t-statistic at 64.61 . The CRRA is estimated to be 2.7884 with a high t-statistic of 7.1709. The Durbin-Watson statistic is acceptable at 1.8555.

The risk-free rate Euler equation produces results that are less satisfactory. Although the discount factor is reasonable at 0.9826 and highly significant statistically ( $t$-statistic of 182.43) the estimated CRRA is perversely negative but turns out to be statistically insignificant (t-statistic: -0.342). Moreover the Durbin-Watson statistic at 1.28 is too low, and denotes the presence of positive serial correlation of the residuals. The reason for such results may arise from the recognized fact that $\mathrm{T}$-securities carry a negative liquidity premium, rendering the risk-free rate to be understated. A lower yield acts as a lower discount factor, which drives the CRRA downward. The reader is reminded that the conclusion from Table 2 was that a lower discount factor is associated with a lower CRRA.

Table 3. Unconditional Estimates of the Rate of Time Preference $\beta$ and the Coefficient of Relative Risk Aversion or CRRA $(\gamma)$.

\begin{tabular}{lccc}
\hline $\begin{array}{l}\text { Total equity return Euler } \\
\text { equation }\end{array}$ & $\beta$ & $\gamma$ & Durbin-Watson \\
\hline $\begin{array}{l}\text { Iterative least squares \& } \\
\text { Seemingly unrelated }\end{array}$ & 0.9661 & 2.7884 & \\
regression & $(64.6087)$ & $(7.1709)$ & 1.8555 \\
$\begin{array}{l}\text { Equity premium Euler } \\
\text { equation }\end{array}$ & {$[0.0000]$} & $\gamma$ & Durbin-Watson \\
$\begin{array}{l}\text { Iterative least squares \& } \\
\text { Seemingly unrelated }\end{array}$ & & 3.8973 & \\
regression & $\beta$ & $(2.4810)$ & 1.6408 \\
$\begin{array}{l}\text { Risk-free return Euler } \\
\text { equation }\end{array}$ & & $\gamma$ & Durbin-Watson \\
$\begin{array}{l}\text { Iterative least squares \& } \\
\text { Seemingly unrelated } \\
\text { regression }\end{array}$ & 0.9826 & -0.04646 & \\
\hline
\end{tabular}

Notes: In parentheses are t-statistics and in brackets are actual p-values. 
Table 4. Conditional Estimates for the Rate of Time Preference $\beta$ and the Coefficient of Relative Risk Aversion or CRRA $(\gamma)$

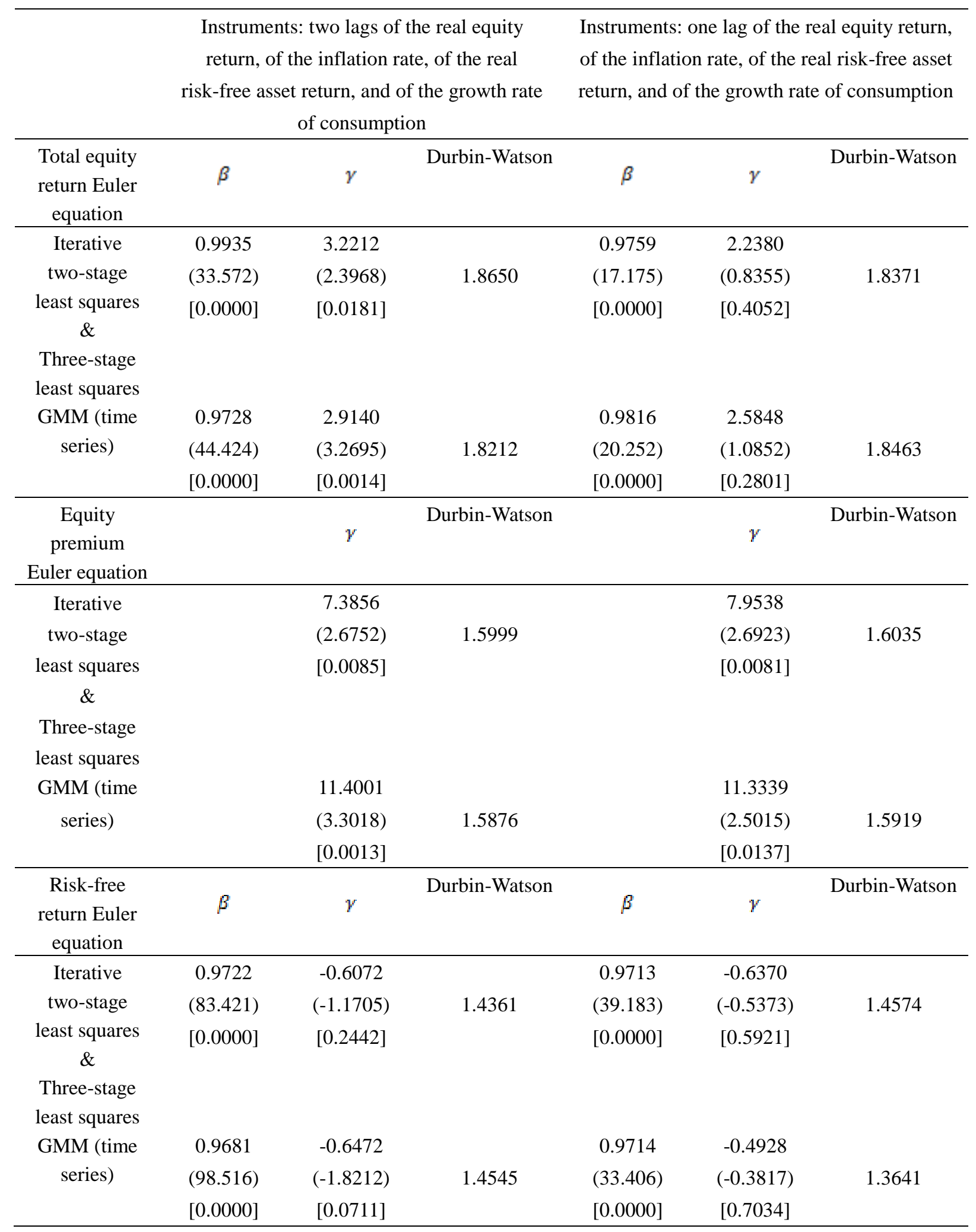

Notes: In parentheses are t-statistics and in brackets are actual p-values. 


\section{Mll Macrothink}

Research in Applied Economics

ISSN 1948-5433

2018, Vol. 10, No. 3

Table 4 portrays the results of estimating each Euler equation by Two-Stage Least Squares (2SLS), and by GMM (time series). Since there is one Euler equation per panel Three-Stage Least Squares (3SLS) produce the same result as Two-Stage Least Squares (2SLS). There are two sets of instrumental variables (IV). The first one includes two lags of all variables, and the second one includes one lag of all variables. It is well known that GMM is very sensitive to the choice of instrumental variables. The first Euler equation, estimated by 2SLS, provides for a CRRA of 3.221 (t-statistic: 2.397), and a discount factor of 0.9935 (t-statistic: 33.572). The Durbin-Watson for this first set of IV is 1.865, which is reasonable. This Euler equation, estimated by GMM, provides a CRRA of 2.914 (t-statistic: 3.270 ) and a discount factor of 0.973 (t-statistic: 44.24). The Durbin-Watson statistic is 1.821. The second set of IV, estimated by 2SLS, shows an estimate of the CRRA of 2.238 (t-statistic: 0.8355$)$ and of the discount factor of 0.976 (t-statistic: 17.18). For this set the Durbin-Watson statistic is 1.837 , also reasonable. With the second set of IV, estimated by GMM, shows an estimate of the CRRA of 2.585 (t-statistic: 1.085) and of the discount factor of 0.982 (t-statistic: 20.28). For this set the Durbin-Watson statistic is 1.846 , which is also reasonable.

The second Euler equation provides for similar results with the two set of instrumental variables. The first set produces a CRRA of 7.3856 ( $\mathrm{t}$-statistic $=2.675$ ) while the second set produces a CRRA of 7.9538 (t-statistic $=2.692$ ). Even the Durbin Watson statistics are close: 1.599 for the first set and 1.604 for the second set. Estimation by GMM, instead of 2SLS and 3SLS, produces respectively a CRRA of 11.400 (t-statistic $=3.302$ ), and11.334 (t-statistic = 2.502), which are also very close to each other. Therefore, and for this Euler equation, the estimates of the CRRA are all higher than 7, estimates which are beyond the acceptable and theoretical range.

The third Euler equation in the table is described equally with the two sets of IV. The CRRAs are small, negative, and statistically insignificant. This applies equally to the two sets of econometric procedure: 2SLS and GMM. However, the estimates of the discount factor are very reasonable ( 0.972 and 0.971 for 2 SLS; and 0.968 , and 0.971 for GMM), and highly significant statistically. The minimum t-statistic for the four estimates is 33.41. This Euler equation supports risk neutrality. Finally the two Durbin-Watson statistics are larger than before at 1.436 and 1.457, for 2SLS, and at 1.457 and 1.364, for GMM.

It seems that the change in instrumental variables affected mostly the estimate of the CRRA of the first, total return, equation. Another discrepancy is that both sets of IV, and both econometric procedures, produce negative and insignificant CRRA for the risk-free Euler equation.

Table 5 presents joint, but unconstrained, estimates. The least squares procedure gives the same results as for the unconditional least squares estimates in Table 3. The reason is obvious: joint estimation by least squares does not take into consideration cross equation dependencies. We are left with four econometric procedures, two different set of IV, three Euler equations, 30 estimates of the CRRA, and 20 estimates of the discount factor. 


\section{Macrothink}

Research in Applied Economics

ISSN 1948-5433

2018, Vol. 10, No. 3

Table 5. Unconstrained Joint Conditional and Joint Unconditional Estimates for the Rate of Time Preference $\beta$ and the Coefficient of Relative Risk Aversion or CRRA $(\gamma)$

\begin{tabular}{|c|c|c|c|c|c|c|}
\hline \multirow[b]{2}{*}{ Iterative least squares } & \multicolumn{3}{|c|}{$\begin{array}{l}\text { Instruments: two lags of the real equity } \\
\text { return, of the inflation rate, of the real } \\
\text { risk-free asset return, and of the growth } \\
\text { rate of consumption }\end{array}$} & \multicolumn{3}{|c|}{$\begin{array}{l}\text { Instruments: one lag of the real equity } \\
\text { return, of the inflation rate, of the real } \\
\text { risk-free asset return, and of the growth } \\
\text { rate of consumption }\end{array}$} \\
\hline & $\beta$ & $\gamma$ & Durbin-Watson & $\beta$ & $\gamma$ & Durbin-Watson \\
\hline Total equity return & $\begin{array}{c}0.9661 \\
(64.6087) \\
{[0.0000]}\end{array}$ & $\begin{array}{c}2.7884 \\
(7.1709) \\
{[0.0000]}\end{array}$ & 1.8555 & $\begin{array}{c}0.9661 \\
(64.6087) \\
{[0.0000]}\end{array}$ & $\begin{array}{c}2.7884 \\
(7.1709) \\
{[0.0000]}\end{array}$ & 1.8555 \\
\hline Risk premium & & $\begin{array}{c}3.8470 \\
(2.4519) \\
{[0.0157]}\end{array}$ & 1.6413 & & $\begin{array}{c}3.8470 \\
(2.4519) \\
{[0.0157]}\end{array}$ & 1.6413 \\
\hline Risk-free return & $\begin{array}{c}0.9826 \\
(182.43) \\
{[0.0000]}\end{array}$ & $\begin{array}{c}-0.0465 \\
(-0.3419) \\
{[0.7330]}\end{array}$ & 1.1277 & $\begin{array}{c}0.9826 \\
(182.43) \\
{[0.0000]}\end{array}$ & $\begin{array}{l}-0.0465 \\
(-0.342) \\
{[0.7330]}\end{array}$ & 1.1277 \\
\hline $\begin{array}{l}\text { Seemingly unrelated } \\
\text { regression }\end{array}$ & $\beta$ & $\gamma$ & Durbin-Watson & $\beta$ & $\gamma$ & Durbin-Watson \\
\hline Total equity return & $\begin{array}{c}0.9685 \\
(89.113) \\
{[0.0000]}\end{array}$ & $\begin{array}{c}1.2317 \\
(4.5775) \\
{[0.0000]}\end{array}$ & 1.8339 & $\begin{array}{c}0.9686 \\
(88.951) \\
{[0.0000]}\end{array}$ & $\begin{array}{c}1.2354 \\
(4.5820) \\
{[0.0000]}\end{array}$ & 1.8341 \\
\hline Risk premium & & $\begin{array}{c}2.5886 \\
(2.3246) \\
{[0.0207]}\end{array}$ & 1.6523 & & $\begin{array}{c}2.6021 \\
(2.3391) \\
{[0.0199]}\end{array}$ & 1.6522 \\
\hline Risk-free return & $\begin{array}{c}0.9809 \\
(185.71) \\
{[0.0000]}\end{array}$ & $\begin{array}{c}0.0583 \\
(0.4364) \\
{[0.6628]}\end{array}$ & 1.0895 & $\begin{array}{c}0.9809 \\
(185.85) \\
{[0.0000]}\end{array}$ & $\begin{array}{c}0.0627 \\
(0.4694) \\
{[0.6391]}\end{array}$ & 1.0881 \\
\hline $\begin{array}{c}\text { Iterative two-stage least } \\
\text { squares }\end{array}$ & $\beta$ & $\gamma$ & Durbin-Watson & $\beta$ & $\gamma$ & Durbin-Watson \\
\hline Total equity return & $\begin{array}{c}0.9935 \\
(33.572) \\
{[0.0000]}\end{array}$ & $\begin{array}{c}3.2212 \\
(2.3968) \\
{[0.0171]}\end{array}$ & 1.8650 & $\begin{array}{c}0.9759 \\
(17.175) \\
{[0.0000]}\end{array}$ & $\begin{array}{c}2.2380 \\
(0.8355) \\
{[0.4040]}\end{array}$ & 1.8371 \\
\hline Risk premium & & $\begin{array}{c}7.3856 \\
(2.6752) \\
{[0.0078]}\end{array}$ & 1.5999 & & $\begin{array}{c}7.9539 \\
(2.6922) \\
{[0.0074]}\end{array}$ & 1.6035 \\
\hline Risk-free return & $\begin{array}{c}0.9722 \\
(83.421) \\
{[0.0000]}\end{array}$ & $\begin{array}{c}-0.6072 \\
(-1.1705) \\
{[0.2426]}\end{array}$ & 1.4361 & $\begin{array}{c}0.9713 \\
(39.183) \\
{[0.0000]}\end{array}$ & $\begin{array}{l}-0.6370 \\
(-0.537) \\
{[0.5914]}\end{array}$ & 1.4574 \\
\hline
\end{tabular}




\begin{tabular}{|c|c|c|c|c|c|c|}
\hline Three-stage least squares & $\beta$ & $y$ & Durbin-Watson & $\beta$ & $\gamma$ & Durbin-Watson \\
\hline \multirow[t]{3}{*}{ Total equity return } & 0.9772 & 1.6089 & & 0.9948 & 2.3316 & \\
\hline & $(40.821)$ & $(1.5805)$ & 1.7854 & (25.385) & (1.1998) & 1.8176 \\
\hline & {$[0.0000]$} & [0.1149] & & {$[0.0000]$} & [0.2310] & \\
\hline \multirow[t]{3}{*}{ Risk premium } & & 5.1196 & & & 5.8448 & \\
\hline & & (2.0560) & 1.6174 & & (2.1610) & 1.6203 \\
\hline & & {$[0.0405]$} & & & [0.0314] & \\
\hline \multirow[t]{3}{*}{ Risk-free return } & 0.9719 & -0.6376 & & 0.9716 & -0.6385 & \\
\hline & (84.139) & $(-1.2416)$ & 1.4554 & (39.615) & $(-0.544)$ & 1.4584 \\
\hline & {$[0.0000]$} & {$[-0.2152]$} & & {$[0.0000]$} & {$[0.5865]$} & \\
\hline GMM (time series) & $\beta$ & $\gamma$ & Durbin-Watson & $\beta$ & $\gamma$ & Durbin-Watson \\
\hline \multirow[t]{3}{*}{ Total equity return } & 0.9915 & 2.9419 & & 1.0014 & 3.0750 & \\
\hline & (119.511) & (8.1123) & 1.8460 & $(43.244)$ & (2.6602) & 1.8716 \\
\hline & {$[0.0000]$} & {$[0.0000]$} & & [0.0000] & {$[0.0082]$} & \\
\hline \multirow[t]{3}{*}{ Risk premium } & & 8.2381 & & & 9.3036 & \\
\hline & & $(4.9920)$ & 1.5948 & & (2.8959) & 1.5960 \\
\hline & & {$[0.0000]$} & & & {$[0.0000]$} & \\
\hline \multirow[t]{3}{*}{ Risk-free return } & 0.9721 & -0.6588 & & 0.95597 & -1.1565 & \\
\hline & $(229.154)$ & $(-4.0623)$ & 1.4685 & (42.015) & $(-1.138)$ & $1.7441^{\circ}$ \\
\hline & [0.0000] & [0.0001] & & {$[0.0000]$} & {$[0.2560]$} & \\
\hline
\end{tabular}

Notes: In parentheses are t-statistics and in brackets are actual p-values.

All discount factors, whatever the procedure, whatever the set of IV, and for the two Euler equations (total return, and risk-free return), are reasonable and range between 0.9661 and 1.0014. Only one estimate is greater than 1 (1.0014) and corresponds to the first Euler equation with the second set of IV, and with GMM estimation. The minimum t-statistic is 17.175 with an actual p-value less than 0.0001. The CRRAs for the first Euler equation (equation 2) are smaller than the CRRAs of the second Euler equation (equation 4). Whereas the first Euler equation has a minimum CRRA of 1.232 and a maximum CRRA of 3.2212, the third Euler equation for the asset premium has a minimum CRRA of 2.5886 and a maximum of 9.3036. Moreover, out of 10 estimates, 6 estimates of the third Euler equation, are higher than five in value. In general the lowest CRRAs are for the seemingly unrelated regressions, and the highest are for the GMM procedures.

As for the risk-free Euler equation (equation 3) all estimates of the CRRA are statistically insignificantly different from zero, and 8 out of 10 are negative. Therefore there is still a prominent equity premium puzzle despite the change in IV and in econometric procedure. And this puzzle extends to the risk-free Euler equations for which the hypothesis of risk neutrality is not rejected. Joint estimation did not produce results that can be counted upon for the refutability of the puzzles. 
Table 6. Constrained Conditional Estimates for the Rate of Time Preference $\beta$ and the Coefficient of Relative Risk Aversion or CRRA $(\gamma)$

\begin{tabular}{|c|c|c|c|c|c|c|}
\hline \multirow[b]{2}{*}{ Iterative least squares } & \multicolumn{3}{|c|}{$\begin{array}{l}\text { Instruments: two lags of the real equity } \\
\text { return, of the inflation rate, of the real } \\
\text { risk-free asset return, and of the growth } \\
\text { rate of consumption }\end{array}$} & \multicolumn{3}{|c|}{$\begin{array}{l}\text { Instruments: one lag of the real equity } \\
\text { return, of the inflation rate, of the real } \\
\text { risk-free asset return, and of the } \\
\text { growth rate of consumption }\end{array}$} \\
\hline & $\beta$ & $\gamma$ & Durbin-Watson & $\beta$ & $\gamma$ & Durbin-Watson \\
\hline & $\begin{array}{c}0.9741 \\
(89.698) \\
{[0.0000]}\end{array}$ & $\begin{array}{c}1.6577 \\
(6.0715) \\
{[0.0000]}\end{array}$ & & $\begin{array}{c}0.9741 \\
(89.698) \\
{[0.0000]}\end{array}$ & $\begin{array}{c}1.6577 \\
(6.0715) \\
{[0.0000]}\end{array}$ & \\
\hline Total equity return & & & 1.8418 & & & 1.8418 \\
\hline Risk premium & & & 1.6598 & & & 1.6598 \\
\hline Risk-free return & & & 1.1036 & & & 1.1036 \\
\hline \multirow[t]{2}{*}{$\begin{array}{c}\text { Seemingly unrelated } \\
\text { regression }\end{array}$} & $\beta$ & $\gamma$ & Durbin-Watson & $\beta$ & $\gamma$ & Durbin-Watson \\
\hline & $\begin{array}{c}0.9688 \\
(306.42) \\
{[0.0000]}\end{array}$ & $\begin{array}{c}0.4287 \\
(2.8064) \\
{[0.0053]}\end{array}$ & & $\begin{array}{c}0.9688 \\
(306.42) \\
{[0.0000]}\end{array}$ & $\begin{array}{c}0.4287 \\
(2.8064) \\
{[0.0053]}\end{array}$ & \\
\hline Total equity return & & & 1.7968 & & & 1.7968 \\
\hline Risk premium & & & 1.6686 & & & 1.6686 \\
\hline Risk-free return & & & 0.8999 & & & 0.8999 \\
\hline \multirow[t]{2}{*}{$\begin{array}{c}\text { Iterative two-stage least } \\
\text { squares } \\
\end{array}$} & $\beta$ & $\gamma$ & Durbin-Watson & $\beta$ & $\gamma$ & Durbin-Watson \\
\hline & $\begin{array}{c}1.0080 \\
(51.710) \\
{[0.0000]}\end{array}$ & $\begin{array}{c}2.7733 \\
(3.1061) \\
{[0.0020]}\end{array}$ & & $\begin{array}{c}1.0501 \\
(30.151) \\
{[0.0000]}\end{array}$ & $\begin{array}{c}5.0332 \\
(2.5812) \\
{[0.0102]}\end{array}$ & \\
\hline Total equity return & & & 1.7952 & & & 1.9923 \\
\hline Risk premium & & & 1.6368 & & & 1.6276 \\
\hline Risk-free return & & & 1.5327 & & & 1.7561 \\
\hline \multirow[t]{2}{*}{ Three-stage least squares } & $\beta$ & $\gamma$ & Durbin-Watson & $\beta$ & $\gamma$ & Durbin-Watson \\
\hline & $\begin{array}{c}0.9802 \\
(113.69) \\
{[0.0000]}\end{array}$ & $\begin{array}{c}0.6614 \\
(1.6469) \\
{[0.1005]}\end{array}$ & & $\begin{array}{c}0.9876 \\
(60.253) \\
{[0.0000]}\end{array}$ & $\begin{array}{c}1.6519 \\
(2.4828) \\
{[0.0135]}\end{array}$ & \\
\hline Total equity return & & & 1.7242 & & & 1.7844 \\
\hline Risk premium & & & 1.6520 & & & 1.6564 \\
\hline Risk-free return & & & 1.0000 & & & 1.2390 \\
\hline \multicolumn{7}{|l|}{ Table 6 continued } \\
\hline GMM (time series) & $\beta$ & $\gamma$ & Durbin-Watson & $\beta$ & $\gamma$ & Durbin-Watson \\
\hline & $\begin{array}{c}1.0074 \\
(692.34) \\
{[0.0000]}\end{array}$ & $\begin{array}{c}2.7290 \\
(16.241) \\
{[0.0000]}\end{array}$ & & $\begin{array}{c}1.0499 \\
(114.50) \\
{[0.0000]}\end{array}$ & $\begin{array}{c}4.3847 \\
(7.5127) \\
{[0.0000]}\end{array}$ & \\
\hline Total equity return & & & 1.7919 & & & 1.9039 \\
\hline Risk premium & & & 1.6371 & & & 1.6334 \\
\hline Risk-free return & & & 1.5254 & & & 1.7501 \\
\hline
\end{tabular}

Notes: In parentheses are t-statistics and in brackets are actual p-values. 


\section{Mll Macrothink}

Research in Applied Economics

ISSN 1948-5433

2018, Vol. 10, No. 3

Table 6 presents the constrained estimation of the three Euler equations. By constrained is meant that one CRRA is estimated by each econometric procedure. In addition one estimate is provided for the discount rate. Here again we use two sets of IV, the same two sets as before. Iterative least squares and seemingly unrelated specifications are not affected by the change in IV. In what concerns the discount factors the two estimations are 0.974 and 0.969 respectively. In what concerns the CRRA the two estimates are 1.658 and 0.429 respectively. All four coefficients are highly significant statistically the maximum actual two-tailed p-value being 0.0053. However the Durbin-Watson statistic is not satisfactory, especially for the third risk-free Euler equation. Since this statistic measures also whether the model is well-specified the model is probably not well-specified.

As for the estimates of the CRRA and discount factor for the rest of the econometric procedures: 2SLS, 3SLS, and GMM, the choice of the IV instruments is critical. In all three cases the CRRA is higher with the second set of IV (first lags of all variables). For example the 2SLS estimates change from 2.773 to 5.033. The 3SLS estimates change from 0.661 to 1.652. The GMM estimates change from 2.729 to 4.385 . Half of the estimates of the discount factor are higher than one, but not by much. Although theoretically it is permissible to have a discount factor higher than one, it is still not well regarded.

If one looks upon the Durbin-Watson statistics, the best model is the last one (GMM), with the second set of IV. The three Durbin-Watson statistics are 1.9039, 1.6334, and 1.7501 respectively for each Euler equation. For this model, however, the discount factor is the highest at 1.0499 .

In general, whereas the estimated discount factors are all reasonable, there is a wide array of estimates for the CRRA. This array is the following: $-1.157,-0.659,-0.638,-0.637,-0.632$, $-0.607,-0.046,0.058,0.063,0.427,0.661,1.232,1.235,1.609,1.652,1.658,2.238,2.332$, $2.589,2.602,2.729,2.773,2,788,2.914,2.942,3.075,3.221,3.847,3.897,4.385,5.033$, $5.120,5.845,7.386,7.954,8.238$, and 9.304 . The average estimate is 2.57 , with a standard error of 0.454 , and a t-test away from zero of 5.660 .

\section{Conclusion}

The business press mentions risk appetite, or its converse risk aversion, as the driving force of fluctuations in stock prices. The literature is lagging behind because it purports to estimate one coefficient of risk aversion, that of the country, or the economy. Lately some research shyly modeled the CRRA to be time-variable or country specific. We add to this literature by assuming that the CRRA is a random variable, characterized by a probability density distribution having a mean and a standard deviation. It is interesting to find out not only the average of risk aversion but also its dispersion. This paper has applied unconditional and conditional estimates of the CRRA, and the discount factor. The econometric procedures adopted are inherently different: OLS, SUR, 2SLS, 3SLS, and GMM. As expected the procedures imply substantially different estimates. To test for robustness the set of instrumental variables necessary for some of these procedures varies with two scenarios. The 
paper argues that all the CRRAs estimated provide information on the true distribution of the CRRA in the population. Therefore, the mean of around 36 estimates of the CRRA in this paper are averaged out and the dispersion measured. The resulting finding is that the CRRA is well estimated to have a mean of 2.57 , and a standard error of 0.454 . The $95 \%$ confidence interval is between 1.68 and 3.46. It is notorious that a $\log$ utility function, i.e. a CRRA of 1 , is not in the interval. Finally, the Jarque-Bera test for the normality of the distribution of the CRRAs fails to reject normality, giving more credence to the notion that the CRRA is a random variable, and that it follows a well-behaved normal distribution.

\section{References}

Azar, S. (2007). Log utility? In Collection of essays in economics. Beirut: Haigazian University Publication.

Azar, S. A. (2006). Measuring relative risk aversion. Applied Financial Economics Letters, 2(5), 341-345. https://doi.org/10.1080/17446540600690151

Azar, S. A. (2010a). Bounds to the coefficient of relative risk aversion. Banking and Finance Letters, 2(4), 391.

Azar, S. A. (2010b). Random risk aversion and the cost of eliminating the cost of the foreign exchange risk of the euro. Economics Bulletin, 30(1), 157-168.

Azar, S. A. (2011). Random risk aversion, the cost of eliminating systematic risk, and risk-free yields. The Review of Financial and Accounting Studies, 1, 5-13.

Azar, S. A. (2015). The precision of unconditional estimators of the equity premium. Accounting and Finance Research, 4(1), 143. https://doi.org/10.5430/afr.v4n1p143

Azar, S. A. (2017a). Risk-free yields, risk aversion, and volatility. International Journal of Economics and Financial Issues, 7(3), 105-112.

Azar, S. A. (2017b). The CCAPM with varying preferences. International Journal of Business and Management, 12(2), 199. https://doi.org/10.5539/ijbm.v12n2p199

Azar, S. A., \& Karaguezian-Haddad, V. (2014). Simulating the market coefficient of relative risk aversion. Cogent Economics \& Finance, 2(1), 990742. https://doi.org/10.1080/23322039.2014.990742

Benninga, S., \& Protopapadakis, A. (1990). Leverage, time preference and the 'equity premium puzzle'. Journal of Monetary Economics, 25(1), 49-58. https://doi.org/10.1016/0304-3932(90)90044-5

Berger, D., \& H. J. Turtle. (2009). Time variability in market risk aversion. The Journal of Financial Research, 32, 285-307. https://doi.org/10.1111/j.1475-6803.2009.01251.x

Bollerslev, T., R. F. Engle, \& J. M. Wooldridge. (1988). A capital asset pricing model with time-varying covariances. Journal of Political Economy, 96, 116-31. 
https://doi.org/10.1086/261527

Chetty, R. (2006). A New Method of Estimating Risk Aversion, American Economic Review, 96, 1821-34. https://doi.org/10.1257/aer.96.5.1821

Chiappori, P.-A., \& Paiella, M. (2011). Relative risk aversion is constant: Evidence from panel data. Journal of the European Economic Association, 9, 1021-1052. http://dx.doi.org/10.1111/jeea.2011.9.issue-6

Conine, T. E., McDonald, M. B., \& Tamarkin, M. (2017). Estimation of relative risk aversion across time. Applied Economics, 49(21), 2117-212. https://doi.org/10.1080/00036846.2016.1231910

Das, S., \& Sarkar, N. (2010). Is the relative risk aversion parameter constant over time? A multi-country study. Empirical Economics, 38, 605-617. http://dx.doi.org/10.1007/s00181-009-0281-y

Evans, D. (2004a), the Elevated Status of the Elasticity of Marginal Utility of Consumption, Applied Economics Letters, 11, 443-7. https://doi.org/10.1080/1350485042000189541

Evans, D. (2004b), a Social Discount Rate for France. Applied Economics Letters, 11, 803-8. https://doi.org/10.1080/1350485042000254638

Evans, D., \& Sezer H. (2004). Social Discount Rates for Six Major Countries, Applied Economics Letters, 11, 557-60. https://doi.org/10.1080/135048504200028007

French, K. R., Schwert, G. W., \& Stambaugh, R. F. (1987). Expected stock returns and $\begin{array}{llll}\text { volatility. Journal of Financial } & \text { Economics, } & 19,\end{array}$ http://dx.doi.org/10.1016/0304-405X(87)90026-2

Kocherlakota, N. R. (1990). On the 'discount' factor in growth economies. Journal of Monetary Economics, 25(1), 43-47. https://doi.org/10.1016/0304-3932(90)90043-4

Kocherlakota, N. R. (1996). The equity premium: It's still a puzzle. Journal of Economic Literature, 34(1), 42-71.

Ljungqvist, L., \& T. J. Sargent. (2004). Recursive Macroeconomic Theory. MIT Press Cambridge, MA.

Lucas, R. E. Jr. (1987). Models of business cycles. Basil Blackwell, Oxford.

Tödter, K.-H. (2008). Estimating the uncertainty of relative risk aversion. Applied Financial Economics Letters, 4, 25-27. http://dx.doi.org/10.1080/17446540701335474

\section{Copyright Disclaimer}

Copyright for this article is retained by the author(s), with first publication rights granted to the journal.

This is an open-access article distributed under the terms and conditions of the Creative Commons Attribution license (http://creativecommons.org/licenses/by/3.0/). 